\title{
A PERCEPÇÃO DE JUSTIÇA ORGANIZACIONAL DISTRIBUTIVA DIANTE DE AÇÕES QUE OFERECEM RECURSOS E OPORTUNIDADES À DIVERSIDADE
}

\author{
1- Jamille Barbosa Cavalcanti Pereira* \\ Doutora em Administração de Empresas pela Universidade Presbiteriana Mackenzie (UPM), Brasil. \\ Professora da Universidade Presbiteriana Mackenzie (UPM), Brasil. \\ jamillebc@uol.com.br \\ http://lattes.cnpq.br/1845493322224049
}

\section{2- Ana Paula de Almeida}

Graduada em Administração de Empresas pela Universidade Presbiteriana Mackenzie (UPM), Brasil. anny138@gmail.com

\section{3- Juliana Garcia Cordeiro}

Graduada em Administração de Empresas pela Universidade Presbiteriana Mackenzie (UPM), Brasil. Analista de Controle de Projetos da Computer Sciences Corporation (CSC), Brasil.

juliana.cordeiro.br@gmail.com

\section{4- Marcia Macedo Junqueira Cestari}

Graduada em Administração de Empresas pela Universidade Presbiteriana Mackenzie (UPM), Brasil. Analista da Politica Comercial da Deca (Divisão da Duratex).

marciamjcestari@hotmail.com

\section{5- Leandro Queiroz Alencar}

Graduado em Administração de Empresas pela Universidade Presbiteriana Mackenzie (UPM), Brasil. Gestor de Contas Key Account- Bombril S/A

queirozalencar@ig.com.br

\section{6- Ademar Luiz Mendonça Neto}

Graduado em Administração de Empresas pela Universidade Presbiteriana Mackenzie (UPM), Brasil. Assistente de Planejamento Financeiro amn15041987@hotmail.com 


\section{A PERCEPÇÃO DE JUSTIÇA ORGANIZACIONAL DISTRIBUTIVA DIANTE DE AÇÕES QUE OFERECEM RECURSOS E OPORTUNIDADES À DIVERSIDADE}

\section{RESUMO}

Este estudo objetivou investigar se as ações organizacionais que oferecem recursos em prol da diversidade (mulheres em geral, pessoas negras e pessoas com deficiência) são percebidas como justas. O referencial teórico utilizado baseou-se na Teoria do Multiprincípio de Miller (1976). Essa teoria defende que a oferta de recursos pode ser considerada justa não somente a partir do princípio da equidade/meritocracia, mas também, a partir dos princípios da igualdade que almeja um destino comum para os indivíduos e do princípio da necessidade que concebe a distribuição de recursos como justa para aquele que possui dificuldade de satisfazer por si só as suas necessidades. Para tanto, foi realizada uma pesquisa exploratória sob o método quantitativo. Os dados foram obtidos de uma escala desenvolvida para esse estudo. A amostra foi de 253 pessoas (52\% mulheres, $84 \%$ de raça branca e $94 \%$ sem deficiência). A análise dos dados baseou-se na estatística descritiva e na inferencial. Os resultados indicaram que as ações em estudo são predominantemente percebidas como justas quando embasadas no princípio da equidade, mas que há diferenças de percepção considerando-se as variáveis: sexo, raça e ser ou não pessoa com deficiência, revelando assim, contribuições relevantes para os estudos de gênero no ambiente organizacional.

\section{Palavras-Chave}

Justiça organizacional, Justiça organizacional distributiva, Diversidade.

\section{THE PERCEPTION OF ORGANIZATIONAL DISTRIBUTIVE JUSTICE IN THE FACE OF ACTIONS THAT PROVIDE RESOURCES FOR DIVERSITY}

\section{ABSTRACT}

This study aimed to investigate whether the organizational actions that offer resources for diversity (women in general, black people and people with disabilities) are perceived as fair. The theoretical framework used was based on the theory Multiprincípio Miller (1976). This theory holds that the distribution of resources can be considered fair not only based on the principle of equity / meritocracy, but also on the principles of equality which aims at a common destination for individuals and the principle of necessity which sees the distribution of resources as fair for one who has difficulties in satisfying your needs for yourself. To this end, it was conducted an exploratory study on the quantitative method. Data were obtained from a scale developed for this study. The sample consisted of 253 persons (52\% women, $84 \%$ Caucasian and $94 \%$ without disabilities). Data analysis was based on the descriptive statistics and inferential. The results indicated that the actions under study are predominantly perceived as fair when based on the principle of equity, but there are differences of perception, considering the gender, race and whether or not people with disabilities, thus revealing important contributions for gender studies in organizational environment.

\section{Keywords}

Organizational justice, Organizational distributive justice, Diversity. 


\section{Introdução}

A sociedade brasileira é considerada heterogênea ou multirracial tendo em vista a formação da sua identidade, tanto cultural como física, uma vez que reflete a mistura de índios, brancos, negros e todas as fusões da raça humana (Romero, 1980). Atualmente ela é constituída de uma composição proporcional de indivíduos considerando-se as características de sexo e raça. Conforme pesquisa do IBGE (2010) 51,04\% da população brasileira é composta de mulheres e $48,96 \%$ de homens, e, considerando as características de cor ou raça, 51,1\% da população brasileira, 98 milhões de indivíduos em números absolutos, declaram-se negros (pretos ou pardos) de acordo com a Pesquisa Nacional por Amostra de Domicílios (Pnad) de 2009. No entanto, essa mistura de sexo e raça não se faz presente na mesma proporção quando analisados os dados de composição demográfica das empresas no contexto organizacional brasileiro.

A última pesquisa sobre o perfil social, racial e de gênero do Instituto Ethos (2010) aponta que a presença feminina nas quinhentas maiores empresas do Brasil teve um crescimento de 2,2 pontos nos cargos executivos nos últimos três anos (13,7\% em 2010 contra 11,5\% em 2007), mas ela ainda não é similar a do homem, além disso, vem sofrendo um decréscimo de participação nos cargos gerenciais (de $24,6 \%$ em 2007 para $22,1 \%$ em 2010), bem como, nos cargos de supervisão (de $37 \%$ em 2007 para 26,8\% em 2010). Quanto à participação das pessoas negras, apesar de ter tido uma evolução positiva em cargos executivos (de 3,5\% em 2007 para 5,3\% verificados em 2010) é ainda muito insignificante se comparada a sua expressividade no país (13,2\% nos cargos de gerência e $25,6 \%$ nos cargos de supervisão). No que diz respeito às pessoas com deficiência a situação é bem pior, pois a participação destas em cargos de direção é de apenas $1,5 \%$. Em meio a esse cenário, o que se percebe é que ainda há uma grande diferença de representatividade de pessoas pertencentes a alguns grupos sociais na estrutura hierárquica das empresas no país, principalmente quando considerados os níveis estratégicos e de maior poder.

Algumas ações organizacionais vêm sendo desenvolvidas a fim de oferecer recursos e oportunidades para os indivíduos pertencentes aos grupos sociais sub-representados. A IBM, por exemplo, possui a diversidade como estratégia integrada aos seus negócios e, por isso, incentiva a formação de alianças de indivíduos pertencentes aos diferentes grupos sociais para que esses possam discutir assuntos dos seus interesses e necessidades, como: a aliança dos empregados para o fortalecimento dos gays, lésbicas, TR e bissexuais. Outro exemplo é o da Accenture que implantou o programa de Inclusão Social e Diversidade. Por meio dessa iniciativa, a empresa desenvolve ações objetivando o crescimento do número de mulheres, estrangeiros, pessoas maiores de 45 anos, pessoas com deficiência e homossexuais no quadro de funcionários e em posições de liderança.

Embora as ações organizacionais voltadas para a diversidade denotem práticas louváveis e até de responsabilidade social corporativa (Sen \& Bhattacharya, 2001), elas também podem ser consideradas práticas discriminatórias e injustas (Wilson, 2006), e quando isso acontece, a empresa fica vulnerável a ser vítima de comportamentos negativos por parte dos funcionários, tais como retaliações (Mendonça \& Tamayo, 2004). Perceber algo como inapropriado ou injusto significa dizer que as crenças de um indivíduo foram transgredidas e a percepção de direitos foi violada, seja como resultado de uma ação ou da omissão de algum agente (Folger,1986).

Pouco se sabe no Brasil qual a percepção de justiça dos indivíduos sobre as ações que estão sendo desenvolvidas em prol da diversidade, especialmente sob a dimensão da justiça distributiva, cujo enfoque é voltado para a distribuição de recursos e oportunidades às mulheres em geral, pessoas negras e pessoas com deficiência. Entende-se assim, que essa é uma lacuna que necessita ser preenchida com a construção de um conhecimento que permita compreender alguns dos mais importantes fenômenos envolvidos nessa temática. Tentar preenchê-la tornou-se o objetivo geral desse trabalho. Secundariamente, buscou-se verificar se a percepção sobre tais ações, com base nos princípios da equidade, da igualdade e da necessidade (Miller, 1976) difere entre os homens e as mulheres.

Entende-se que os resultados obtidos deste trabalho abrem novas frentes de investigações tanto sob a perspectiva normativa, pois ampliam os estudos sobre o constructo da percepção de justiça organizacional distributiva, quanto na perspectiva prescritiva, na medida em que oferecem contribuições para desenvolvimento de uma escala para diagnosticar reações das pessoas diante de ações organizacionais voltadas à diversidade. 


\section{Ações Organizacionais Voltadas à Diversidade}

As ações organizacionais voltadas à diversidade referem-se neste trabalho àquelas que se destinam a oferecer recursos e oportunidades às pessoas provenientes de grupos sociais sub-representados. Dessa forma, enquadram-se nessa designação as ações afirmativas e as ações decorrentes de iniciativas ou modelos de gestão empresariais.

Conforme ressalta Moehlecke (2002), o termo ação afirmativa tem origem nos Estados Unidos nos anos 60, mas expandiu-se para os países da Europa Ocidental, Índia, Malásia, Austrália, Canadá, Nigéria, África do Sul, Argentina, Cuba e recentemente no Brasil. Nesses diferentes contextos, tal termo assumiu formas como: ações voluntárias, de caráter obrigatório ou uma estratégia mista; programas governamentais ou privados; leis e orientações a partir de decisões jurídicas ou agências de fomento e regulação. Seu públicoalvo variou de acordo com as situações existentes e abrangeu grupos como minorias étnicas, raciais e mulheres. As principais áreas contempladas são o mercado de trabalho, com a contratação, a qualificação e a promoção de funcionários; o sistema educacional, especialmente o ensino superior; e a ação política. A ação afirmativa envolve o sistema de cotas, que consiste em estabelecer um determinado número ou percentual a ser ocupado em área específica por grupo(s) definido(s), o que pode ocorrer de maneira proporcional ou não e de forma mais ou menos flexível.

Para Guimarães (1997) as ações afirmativas estão ligadas às sociedades democráticas que tenham no mérito individual e na igualdade de oportunidades seus principais valores. Elas justificam-se pela busca da restituição de uma igualdade que foi rompida ou que nunca existiu entre os grupos sociais. Nesse sentido, tais ações objetivam resgatar a cidadania dos que estão marginalizados de toda a sociedade e do sistema como um todo, ou como diz Bateman e Snell (2008), resgatar a cidadania dos que foram historicamente discriminados.

Há duas teorias que procuram justificar a existência das ações afirmativas: a da Justiça Distributiva que tem por pleito de justiça o tempo presente por meio de políticas públicas que promovem e efetivam o princípio da igualdade como direito fundamental e a Justiça Compensatória que reivindica a reparação de danos ocorridos no passado em relação aos membros de determinado grupo minoritário (Kaufmann, 2007). Subjacente às justificativas para a existência de tais ações está a ideia de que a desigualdade entre os grupos sociais não é um fenômeno natural, mas resultado das diversas interações sociais (Valentim, 2005); assim, há uma necessidade de intervenção política na reversão do quadro de desigualdade que se observa em uma dada sociedade (Alves \& Galeão Silva, 2004). Mas, há na literatura a defesa do equilíbrio na representação das diferentes categorias sociais nas mais diversas áreas da sociedade é motivo mais que suficiente para que tais ações políticas sejam extintas, sob pena de maltratarem a necessidade de um tratamento equânime entre as pessoas, por estabelecerem distinções não mais devidas (Guimarães, 1997; Kaufmmann, 2007).

Uma das críticas realizadas diante das ações afirmativas aplicadas ao contexto organizacional é que muitas empresas aderem a essas ações por obrigação, apenas para cumprir a lei, o que denota uma não aceitação natural das mesmas (Alves \& Galeão Silva, 2004). Além disso, cumprir tais ações não significa trabalhar a diversidade (Cox, 1991; Thomas, 1996).

Para Cox (1991), trabalhar com a diversidade no contexto organizacional vai além de simplesmente implantar políticas de inserção de minorias. Para que esse trabalho ocorra de forma efetiva é necessário criar um modelo de gestão que possibilite e garanta a igualdade de oportunidades aos indivíduos provenientes de grupos sociais sub-representados por meio de algumas ferramentas e ações, tais como: desenvolvimento de práticas de carreira, mudanças na administração de avaliação de performance e recompensas, políticas de RH, mudanças nos benefícios, práticas de aconselhamento para o desenvolvimento profissional (mentoring), desenvolvimento de seminários sobre igualdade de oportunidades e administração de conflitos.

Assim como as ações afirmativas, a gestão da diversidade foi acontecendo inicialmente nas organizações estadunidenses e foi se alastrando pelo mundo, porém, não de forma simples e nem natural. Bond e Pyle (1998) ressaltam que esse fenômeno vem surgindo em meio a muitos dilemas que têm impedido o seu pleno desenvolvimento, tais como: (a) contradições sobre o quanto essa gestão é ou não justa; (b) reações opostas as suas propostas, tais como, as de discriminação reversa e (c) limitadas mudanças na cultura das organizações que poderiam reforçar sua sustentabilidade. 
Assim como Cox (1991) há outros autores que defendem o princípio de justiça baseado na igualdade por meio das ações organizacionais voltadas à diversidade, pois entendem que os grupos sociais não têm as mesmas oportunidades na sociedade e possuem necessidades diferentes que precisam ser atendidas (Ivancevich \& Gilbert, 2000; Thomas, 1996). Mas há quem discorde por acreditar que todos têm condições similares de desenvolvimento.

Kandola e Fullerton (1994) entendem que a gestão da diversidade deva ser embasada pelo princípio da equidade. Sob essa perspectiva, o que importa é ser competente e efetivo na geração de resultados para a organização, ou seja, o que importa é a meritocracia. Para esses autores, desenvolver tal gestão se resume em uma palavra: MOSAIC - (Mission and Values; Objective and fair processes; Skilled workforce, sware and fair; Active flexibility; Individual focus; Culture that empowers). Na prática, a organização sob essa abordagem deverá atender às necessidades de todos os empregados e não somente as dos considerados diversos; além disso, deverá ter objetividade e processos justos; garantir que o recrutamento e a seleção, bem como, as promoções e as avaliações sejam auditados para assegurar justiça para todos; reconhecer as habilidades e o desenvolvimento de toda a força de trabalho como necessárias para o crescimento da organização; garantir a flexibilidade de modelos de trabalho e de locais de trabalho; oferecer benefícios para todos e não somente para alguns grupos específicos; focar no indivíduo e em um modelo de cultura que possibilite aos indivíduos tomar decisões, participar e serem encorajados a ouvir e a agir entre eles.

As principais justificativas para a realização de uma gestão de diversidade baseada na equidade são baseadas na crença de que a organização estará privilegiando uns grupos em detrimento de outros ao dar preferência a categorias de grupos sociais na realização de determinados processos (Linnehan \& Konrad, 1999). Para esses autores, isso ocasiona estigmatização, preconceito e discriminação em relação aos que usufruem dos recursos e oportunidades oferecidos pela empresa. Além do mais, para a organização essas reações podem reduzir o comprometimento, a produtividade e aumentar o turnover dos indivíduos não favorecidos.

Diante do exposto fica a curiosidade em saber qual a percepção de justiça que as pessoas têm das ações organizacionais voltadas à diversidade considerando-se o contexto organizacional brasileiro.

\section{A Percepção de Justiça Organizacional: uma breve definição}

O que é justo no ambiente organizacional? Essa pergunta foi elaborada pela primeira vez por Jerald Greenberg em 1987, quando a utilizou para explicar a percepção de justiça interna a uma organização e como os indivíduos reagem e se comportam perante tal percepção (Assmar \& Ferreira, 2005).

Como ressaltam Almeida, Silva e Santos (2006) os estudos na área de justiça organizacional se iniciaram com os estudos de Adams em 1963, quando esse passou a estudar a maneira como os indivíduos percebem a proporção entre os seus esforços e investimentos no trabalho e as recompensas por ele recebidas comparando-as com seus colegas de trabalho. Sob essa abordagem ao perceber uma injustiça no trabalho o indivíduo procura responder a ela buscando o estabelecimento de um novo equilíbrio através de ações que compensem a injustiça percebida, como diminuir a quantidade de trabalho, descomprometerse com a empresa ou com os responsáveis pela decisão na empresa, deixar de auxiliar colegas, cometer faltas ou atrasos, chegar até a cometer atos mais extremos como sabotagens e violência no local de trabalho.

A percepção do que é justo ou injusto no cotidiano de um indivíduo tem por base valores, princípios éticos, morais e noções de certo e errado para analisar cada conjuntura em que ele está sendo envolvido (Assmar \& Ferreira, 2005). Perceber o que é justo no ambiente organizacional, seria sob essa perspectiva, uma grande justificativa de incentivo ou de motivação para as pessoas que nele trabalham.

Pesquisadores têm utilizado quatro dimensões para definir a justiça organizacional: a distributiva relacionada à distribuição de recursos/resultados, a processual relacionada aos processos desenvolvidos na organização, ou seja, a justiça dos meios usados para alcançar os fins; a interacional que incide sobre o grau em que o superior adota um tratamento digno e respeitador para com os seus colaboradores e a informacional que é centrada no grau em que o superior fornece informações e explica/justifica as decisões que afetam as pessoas (Colquitt, 2001). Nesse trabalho a ênfase dada ao estudo sobre a justiça organizacional distributiva justifica-se pelo objetivo geral que lhe é inerente, ou seja, identificar a percepção de justiça dos indivíduos diante das ações organizacionais que oferecem ou distribuem recursos e oportunidades aos indivíduos que pertencem aos grupos de mulheres em geral, de pessoas negras e de pessoas com deficiência. As características que definem esse tipo de percepção serão descritas a seguir. 


\subsection{A Percepção de Justiça Organizacional Distributiva}

A justiça organizacional distributiva foca os fins alcançados ou obtidos pelo indivíduo em uma organização (Rego, 2002). Inicialmente o conceito foi estudado por Homans (1961) para quem o indivíduo percebe como justo ou injusto os resultados de suas relações de acordo com a balança entre o investimento e o retorno. Assim sendo, torna-se justo quando um indivíduo recebe algo equivalente ao que ele investiu na relação de troca que estabelece com seus colegas. Os estudos de Adams realizados em 1963 trouxeram uma grande contribuição ao definir justiça distributiva como a análise do quanto são justas as recompensas direcionadas aos funcionários (Assmar \& Ferreira, 2005).

Não há uma única definição para a justiça organizacional distributiva. Por meio de um estudo taxonômico é possível verificar que a justiça organizacional distributiva é delimitada por duas dimensões: a macro ou microjustiça e pela unidimensionalidade ou pela multidimensionalidade. As combinações dessas dimensões originam quatro possibilidades para compreender a justiça distributiva: a macro e unidimensional - Abordagem Utilitarista; a macro e multidimensional - Teoria da Justiça de Rawl's; a micro e unidimensional - Teoria da Equidade e a micro e multidimensional - Teoria de Miller / Abordagem do Multiprincípio (Sabbagh, 2002).

A justiça distributiva baseada na macrojustiça tem foco na organização social, ou seja, no comportamento da sociedade como um todo. É caracterizada por duas teorias que tomam como base os princípios da utilidade e da igualdade. A teoria da utilidade é baseada nos valores básicos da vida humana, como a felicidade e bem-estar (Sabbagh, 2002). Já a micro justiça tem foco no comportamento do indivíduo. Ela também se desdobra em duas teorias: a da equidade e a do multiprincípio. Na primeira, as pessoas comparam sua taxa ou referência de esforços, contribuições e habilidades para determinar se os resultados obtidos são justos ou não, ou seja, tem como base a meritocracia individual. A Teoria do Multiprincípio, escolhida neste trabalho como Teoria de base, propõe três diferentes princípios: o da equidade, o da igualdade e o da necessidade, ela defende que não há um único princípio válido que possa regular a distribuição de recursos sociais em todos os tipos de sociedade (Miller, 1976).

A equidade sob a Teoria do Multiprincípio tem por pressuposto a ideia de que o direito de todos é proporcional aos esforços desprendidos diante do desempenho realizado, ou seja, do mérito. O mérito é usualmente baseado nas características presentes ou passadas dos indivíduos e não no futuro. Dessa forma, as pessoas comparam seus esforços para determinar se os resultados que elas têm recebido são ou não justos. Já o princípio da igualdade pressupõe que diferentes membros de um grupo têm valores iguais enquanto indivíduos e criam condições ótimas para a manutenção da mútua autoestima. Sob essa ótica, a busca por um destino comum a todos os indivíduos torna-se um fim em si, e por meio dele, é necessário promover a solidariedade, a cooperação e a harmonia (Lerner, 1975). O princípio da necessidade, por sua vez, pressupõe que a distribuição de recursos sociais deverá ser feita de acordo com as necessidades individuais. Esse princípio luta não só por reduzir o sofrimento individual, que deriva da incapacidade das pessoas de satisfazer suas próprias necessidades básicas; por exemplo, as físicas, mas também das necessidades secundárias tais como a de desenvolvimento intelectual e emocional (Deutsch, 1985). Schwartz (1975) enfatiza que esse princípio é relatado por normas humanistas preocupadas com o bemestar do ser humano e por normas de responsabilidade social que se referem à responsabilidade por outros, mesmo que não se tenha contato com eles. O princípio da necessidade é frequentemente aplicado em legislações sociais voltadas para uma proteção aos trabalhadores, leis de salário mínimo, seguro saúde e de desemprego.

\subsubsection{A percepção de Justiça Organizacional Distributiva diante de Ações Voltadas à Diversidade}

$\mathrm{Na}$ literatura estrangeira é possível encontrar estudos que relacionam a percepção de justiça distributiva diante de ações organizacionais voltadas à diversidade. Richard e Kirb (1997) realizaram um estudo sobre a percepção de justiça de estudantes estadunidenses sobre as ações organizacionais voltadas à diversidade e descobriram que tal percepção modificava-se de acordo com o sexo e a raça dos que eram beneficiários de tais ações. Os resultados desse estudo revelaram que essas ações quando voltadas para os homens negros eram vistas como mais justas do que as voltadas para as mulheres brancas.

Outros estudos estrangeiros revelaram que homens brancos percebem mais as ações voltadas à diversidade como não justas do que os demais grupos sociais, assim como pessoas consideradas diversas (pertencentes a grupos sociais sub-representados) têm uma percepção de justiça sobre tais ações de uma 
forma menos rigorosa do que àqueles considerados não diversos. Isso foi claro quanto à etnia, mas menos claro quanto ao sexo (Leck, Saunders \& Charbonneau, 1996; Vermeulen \& Coetzee, 2006).

No Brasil, foi localizado um único estudo empírico realizado por Pereira (2008) sobre a percepção de justiça organizacional diante das ações organizacionais voltadas para a diversidade. Após uma pesquisa empírica com 412 indivíduos provenientes de 18 cidades das cinco regiões políticas do Brasil, a pesquisadora descobriu que tais ações foram predominantemente consideradas justas quando oferecem recursos e oportunidades iguais para todos os indivíduos, independentemente do sexo, raça ou de qualquer outro atributo de diversidade, e quando, são voltadas para atender às necessidades das pessoas com deficiência. O princípio da meritocracia foi prevalecente sobre os princípios da igualdade de oportunidade e o da necessidade.

Os dados obtidos dos estudos estrangeiros e, principalmente, do contexto brasileiro sobre a percepção de justiça organizacional voltada para as ações organizacionais voltadas à diversidade deram margem para pressupor que tal percepção difere entre os indivíduos, principalmente quando considerada a variável sexo. Com base nisso, foram elaboradas as seguintes hipóteses para este trabalho:
$\mathrm{H}_{1}$ : Há diferença de percepção de justiça organizacional entre os homens e as mulheres diante das ações organizacionais que oferecem recursos e oportunidades à diversidade baseadas no princípio da equidade.

$\mathrm{H}_{2}$ : Há diferença de percepção de justiça organizacional entre os homens e as mulheres diante das ações organizacionais que oferecem recursos e oportunidades à diversidade baseadas no princípio da igualdade de oportunidade.
$\mathrm{H}_{3}$ : Há diferença de percepção de justiça organizacional entre os homens e as mulheres diante das ações organizacionais que oferecem recursos e oportunidades à diversidade baseadas no princípio da necessidade.

\section{Procedimentos Metodológicos}

\subsection{O Instrumento Utilizado}

O instrumento utilizado neste trabalho para mensurar a percepção das ações organizacionais voltadas à diversidade foi construído com vinte e quatro itens. Ele foi operacionalizado a partir de uma escala de seis pontos, do tipo Likert: discordo totalmente [1]; discordo [2]; discordo parcialmente [3]; concordo parcialmente [4]; concordo [ 5] e concordo totalmente [6]. O posicionamento dos sujeitos diante dos itens da escala torna possível saber, sob que princípios um sujeito percebe as ações organizacionais em prol da diversidade como justas, se as baseadas: na equidade (itens: 4,8,10,19,21 e 23), na igualdade (itens 3, 5 , $7,9,12,13,15,16,17$ e 22) ou na necessidade (itens 1, 2, 6, 11, 14, 18 e 20). A elaboração desse instrumento seguiu as seguintes etapas: (a) levantamento de informações em estudos anteriores sobre escalas de percepção de justiça organizacional aplicadas às ações em prol da diversidade; (b) definição dos componentes norteadores (Pasquali, 2004); (c) validação semântica e de conteúdo do instrumento utilizado; (d) pré-teste; (e) validação de conteúdo.

(a) Estudos anteriores sobre escalas de Percepção de Justiça Organizacional Distributiva aplicada às ações em prol da diversidade

Após uma vasta revisão bibliográfica foi possível localizar na literatura três escalas de percepção de justiça organizacional voltadas a ações em prol da diversidade. A primeira delas, desenvolvida no Canadá por Leck, Saunders e Charbonneau (1996) tem como foco não só a percepção de justiça organizacional distributiva, mas também a processual. A segunda, desenvolvida na África do Sul por Vermeulen e Coetzee (2006) mensura a percepção de três dimensões da justiça organizacional: a distributiva, a processual e a interacional. E a terceira, desenvolvida no Brasil por Pereira (2008), tem como foco a percepção de quatro dimensões da justiça organizacional: a distributiva, a processual, a interacional e a informacional. As duas primeiras escalas, apesar de mensurarem a justiça distributiva, contemplavam itens que refletiam um contexto cultural bem diferente do existente no Brasil. A escala desenvolvida por Pereira (2008), apesar de contemplar a Teoria do Multiprincípio, apresenta apenas um item para cada um dos princípios em estudo (equidade, igualdade e necessidade). Desse modo, tornou-se necessário desenvolver uma escala para o 
estudo proposto nesse trabalho. As escalas citadas foram fontes muito importantes para identificar os componentes que nortearam a construção dos itens inerentes às dimensões encontradas desse constructo.

(b) Definição dos componentes norteadores e critérios para a construção dos itens da escala

Os componentes norteadores para a construção da escala em estudo contemplaram os recursos, os benefícios e as oportunidades que são oferecidos pelas ações organizacionais em prol da diversidade. A construção dos itens foi baseada nos três princípios da justiça distributiva, conforme a Teoria do Multiprincípio (Miller, 1976). Na Figura 1 há uma descrição da caracterização de tais princípios, bem como das ações a serem mensuradas e do referencial bibliográfico utilizado em tal construção.

Os grupos sociais escolhidos na escala para representar a diversidade foram os das mulheres em geral, o das pessoas negras e o das pessoas com deficiência. Dados do último Perfil social, racial e de gênero das 500 maiores empresas do Brasil e suas ações afirmativas realizado pelo Instituto Ethos (2010) revelaram que representantes de tais grupos não têm as mesmas oportunidades que os homens brancos de serem representados nas funções hierárquicas de poder das quinhentas maiores empresas do Brasil. Dados do Retrato das Desigualdades de Gênero e Raça (IPEA, 2008), um estudo realizado entre 1993 e 2007 pelo Instituto de Pesquisa Econômica Aplicada - IPEA em parceira com a Secretaria Especial de Políticas para as Mulheres- SPM e com o Fundo de Desenvolvimento das Nações Unidas para a Mulher - UNIFEM também realçam não só a falta de oportunidades desses grupos, bem como realça que as diferenças de necessidades dos mesmos precisam ser consideradas para que estes possam se desenvolver na mesma proporção do desenvolvimento dos homens brancos nas organizações. Nesse sentido, entende-se que a realidade apresentada por esses estudos justifica a citação de tais grupos sociais na escala.

\begin{tabular}{|c|c|c|c|c|}
\hline $\begin{array}{c}\text { Componente } \\
\text { norteador }\end{array}$ & $\begin{array}{l}\text { Princípios de } \\
\text { justiça }\end{array}$ & $\begin{array}{l}\text { Caracterização dos } \\
\text { princípios de justiça }\end{array}$ & Itens da escala & $\begin{array}{l}\text { Referencial } \\
\text { bibliográfico }\end{array}$ \\
\hline \multirow[t]{3}{*}{$\begin{array}{c}\text { Oferta de } \\
\text { recursos e } \\
\text { oportunidades } \\
\text { em prol da } \\
\text { diversidade }\end{array}$} & Equidade & $\begin{array}{c}\text { Os recursos e } \\
\text { oportunidades serão } \\
\text { ofertados de forma justa } \\
\text { pela empresa de acordo } \\
\text { com as contribuições dos } \\
\text { seus colaboradores, ou seja, } \\
\text { de acordo com o mérito } \\
\text { individual. } \\
\text { (Deutsch, 1985; Leventhal, } \\
\text { 1976) }\end{array}$ & $\begin{array}{l}\text { Seis itens para mensurar } \\
\text { as ações que oferecem } \\
\text { oportunidades de } \\
\text { contratação, de promoção, } \\
\text { de desenvolvimento de } \\
\text { carreira, benefícios, } \\
\text { aconselhamentos e } \\
\text { comitês de apoio para } \\
\text { todas as pessoas } \\
\text { indistintamente }\end{array}$ & $\begin{array}{c}\text { As organizações } \\
\text { para serem justas } \\
\text { não podem oferecer } \\
\text { recursos e } \\
\text { oportunidades } \\
\text { diferentes para os } \\
\text { seus colaboradores } \\
\text { (Kandola e } \\
\text { Fullerton, 1994; } \\
\text { Linnehan e Konrad, } \\
\text { 1999) }\end{array}$ \\
\hline & Igualdade & $\begin{array}{c}\text { Os recursos e } \\
\text { oportunidades serão } \\
\text { ofertados de forma justa } \\
\text { pela empresa, se estes } \\
\text { forem similares para todos } \\
\text { os indivíduos de modo que } \\
\text { estes possam ter a condição } \\
\text { de gerar igualmente os } \\
\text { resultados esperados no } \\
\text { trabalho } \\
\text { Lerner, (1975) }\end{array}$ & $\begin{array}{c}\text { Nove itens para } \\
\text { mensurar ações } \\
\text { organizacionais que } \\
\text { oferecem oportunidades } \\
\text { de contratação, de } \\
\text { promoção, de } \\
\text { desenvolvimento de } \\
\text { carreira para mulheres, } \\
\text { para pessoas com } \\
\text { deficiência e para as } \\
\text { pessoas negras. }\end{array}$ & $\begin{array}{c}\text { As organizações } \\
\text { para serem justas } \\
\text { precisam criar } \\
\text { recursos e } \\
\text { igualdade de } \\
\text { oportunidades entre } \\
\text { os seus } \\
\text { colaboradores } \\
\text { (Cox, 1991; } \\
\text { Ivancevich \& } \\
\text { Gilbert, 2000) }\end{array}$ \\
\hline & Necessidade & $\begin{array}{c}\text { Os recursos e } \\
\text { oportunidades serão } \\
\text { ofertados de forma justa } \\
\text { pela empresa, se esta } \\
\text { reduzir o sofrimento dos que } \\
\text { não conseguem satisfazer } \\
\text { suas necessidades por si } \\
\text { mesmos (as básicas, as } \\
\text { intelectuais e as emocionais) } \\
\text { Deutsch (1985) }\end{array}$ & $\begin{array}{c}\text { Nove itens para } \\
\text { mensurar as ações } \\
\text { organizacionais que } \\
\text { oferecem benefícios, } \\
\text { aconselhamentos e } \\
\text { comitês de apoio para os } \\
\text { grupos das mulheres, das } \\
\text { pessoas com deficiência e } \\
\text { o das pessoas negras }\end{array}$ & $\begin{array}{c}\text { As organizações } \\
\text { para serem justas } \\
\text { precisam atender } \\
\text { as diferentes } \\
\text { necessidades dos } \\
\text { seus colaboradores } \\
\text { (Thomas, 1996) }\end{array}$ \\
\hline
\end{tabular}

Figura 1 - Critérios para a construção dos itens da escala de percepção de justiça distributiva sobre as ações organizacionais voltadas à diversidade

Fonte: Elaborado pelos autores 


\section{(c) Validade Semântica do Instrumento Utilizado}

Para a validação semântica da escala utilizada neste estudo foi realizada a partir da submissão do instrumento à análise de 03 juízes: mestres e doutores professores na área da Administração que verificaram não só o conteúdo dos itens como a semântica dos mesmos. Cada juiz recebeu um formulário onde para cada item do instrumento ele deveria designar notas de 0 a 10 para dois quesitos: pertinência dos itens quanto ao conteúdo e clareza do texto, ou seja, esses juízes deveriam avaliar se os itens faziam referência. O resultado foi positivo quanto ao conteúdo, mas revelou restrições quanto à compreensão de alguns termos. Após sofrer ajustes o instrumento foi submetido ao pré-teste.

\section{(d) Pré-Teste}

O pré-teste foi realizado em uma amostra de 247 indivíduos ( $84 \%$ com superior completo/incompleto, $59 \%$ com idade entre 21 e 30 anos, 59\% de mulheres, $85 \%$ pessoas brancas e $92 \%$ sem deficiência). O perfil predominante era, portanto, de mulheres estudantes do curso de Administração ou recém formadas. O instrumento foi aplicado presencialmente e foi solicitada aos respondentes uma análise de cada item quanto à sua compreensão. Após o consentimento de todos os indivíduos de que os itens estavam claros foi desenvolvido o terceiro procedimento para a validação do instrumento, o da análise de consistência interna dos constructos.

(e) Validação de Conteúdo

Tabela 1:

Matriz fatorial para a percepção de justiça organizacional distributiva

\begin{tabular}{|c|c|c|c|}
\hline & \multicolumn{3}{|c|}{ Componentes Principais } \\
\hline & Fator 1 & Fator 2 & Fator 3 \\
\hline \multicolumn{4}{|l|}{ As ações organizacionais em prol da diversidade são justas quando... } \\
\hline 16 - ...ampliam oportunidades para o desenvolvimento profissional das pessoas negras. & 0,83 & & \\
\hline 12 - ....ampliam oportunidades de contratação para as pessoas negras em cargos de comando. & 0,81 & & \\
\hline 13 - ....ampliam oportunidades para o desenvolvimento profissional das mulheres. & 0,80 & & \\
\hline 3 - ...ampliam oportunidades de promoção para as pessoas negras. & 0,79 & & \\
\hline 6 - ...oferecem comitês (reuniões) para identificar as necessidades das pessoas negras & 0,76 & & \\
\hline $\begin{array}{l}18 \text { - ...oferecem um programa específico de aconselhamento profissional para atender às necessidades } \\
\text { das pessoas negras. }\end{array}$ & 0,76 & & \\
\hline 24 - ... oferecem benefícios diferenciados para atender às necessidades das pessoas negras. & 0,73 & & \\
\hline 9 - ...ampliam oportunidades de contratação para as mulheres em cargos de comando. & 0,72 & & \\
\hline 7 - ...ampliam oportunidades de promoção para as mulheres. & 0,69 & & \\
\hline $\begin{array}{l}14 \text { - ...oferecem um programa específico de aconselhamento profissional para atender às necessidades } \\
\text { das mulheres. }\end{array}$ & 0,65 & & \\
\hline 20 - ...oferecem benefícios diferenciados para atender às necessidades das mulheres. & 0,50 & & \\
\hline $\begin{array}{l}\text { 2- ...oferecem um programa específico de aconselhamento profissional para atender às necessidades } \\
\text { das pessoas com deficiência. }\end{array}$ & & 0,70 & \\
\hline 22 - ...ampliam oportunidades para o desenvolvimento profissional das pessoas com deficiência. & & 0,67 & \\
\hline 11 - ...oferecem benefícios diferenciados para atender as necessidades das pessoas com deficiência. & & 0,66 & \\
\hline 17 - ... ampliam oportunidades de promoção para as pessoas com deficiência. & & 0,66 & \\
\hline 15 - ...oferecem comitês (reuniões) para identificar as necessidades das pessoas com deficiência. & & 0,63 & \\
\hline 5 - ....ampliam oportunidades de contratação para as pessoas com deficiência em cargos de comando. & & 0,58 & \\
\hline $\begin{array}{l}19 \text { - ...oferecem a todos os indivíduos as mesmas oportunidades para o desenvolvimento profissional } \\
\text { independente de sexo, raça ou o ser ou não pessoa com deficiência }\end{array}$ & & & 0,89 \\
\hline $\begin{array}{l}23 \text { - ...oferecem a todos os indivíduos as mesmas oportunidades de promoções independente de sexo, } \\
\text { raça ou ser ou não ser pessoa com deficiência }\end{array}$ & & & 0,83 \\
\hline $\begin{array}{l}21 \text { - ...oferecem a todos os indivíduos os mesmos benefícios independentemente de sexo, raça e ser ou } \\
\text { não pessoa com deficiência. }\end{array}$ & & & 0,75 \\
\hline $\begin{array}{l}4 \text { - ... oferecem a todos os indivíduos as mesmas oportunidades de contratação independente de sexo, } \\
\text { raça ou o ser ou não pessoa com deficiência. }\end{array}$ & & & 0,73 \\
\hline $\begin{array}{l}8 \text { - ... oferecem a todos os indivíduos um mesmo programa de aconsel hamento profissional independente } \\
\text { de sexo, raça ou o ser ou não pessoa com deficiência. }\end{array}$ & & & 0,67 \\
\hline
\end{tabular}

Método de Extração: Análise dos Componentes Principais. Método de Rotação: Varimax.

a. Rotação convergiu em 5 interações.

A verificação do conteúdo do instrumento foi feita a partir da técnica estatística de análise fatorial, uma vez que ela exclui variáveis que tenham problemas de multicolinearidade. A extração dos fatores foi 
realizada pelo método dos componentes principais e pelas extrações dos três fatores identificados na literatura (princípios de justiça baseados na equidade, na igualdade e na necessidade). Esses foram confirmados a partir do gráfico scree plot. A rotação utilizada foi a Varimax e optou-se por manter os fatores com cargas fatoriais acima de 0,60 consideradas muito significativas para uma amostra acima de 250 indivíduos (Hair et al., 2003). Após a primeira rodada verificou-se que as variáveis da escala estavam adequadas para tal procedimento estatístico por apresentarem correlações satisfatórias na anti-imagem entre 0,822 e 0,948 maiores do que 0,5 (MAS > 0,5). Após a realização de três rodadas houve a eliminação de dois itens (1 e 10) ficando a escala com 22 itens. O estudo da fatorabilidade revelou um KMO (KaiserMeyer-O/kin) de 0,863 e o teste de esfericidade de Bartlett (qui-quadrado aproximado $=3158,099 ; p<$ 0,01 ). O percentual de variância explicada pelo instrumento foi de $57,62 \%$. Os procedimentos adotados para a extração de três fatores indicaram os mesmos números de fatores, o mesmo se deu no gráfico scree plot, no entanto, esses fatores não refletiram os três princípios de justiça encontrados na literatura (equidade, igualdade e necessidade).

As ações organizacionais em prol da diversidade foram percebidas como justas não pelos princípios de justiça em si, mas a partir dos grupos que são beneficiados pelas mesmas. Em dois dos fatores obtidos os princípios de justiça de igualdade e da necessidade foram agrupados, isto é, não foram sequer diferenciados entre si. O que não aconteceu com o princípio da equidade, este foi devidamente reconhecido conforme descrição apresentada na literatura (ver Tabela 1):

- O fator 1 representou a percepção de justiça distributiva diante das ações organizacionais desenvolvidas em prol da diversidade com base nos princípios de necessidade e de igualdade oferecidas para as mulheres e pessoas negras $(\alpha=0,927)$.

- O fator 2 representou a percepção de justiça distributiva diante das ações organizacionais desenvolvidas em prol à diversidade com base nos princípios de necessidade e de igualdade oferecidas para as pessoas com deficiência $(\alpha=0,784)$.

O fator 3 representou a percepção de justiça distributiva diante das ações organizacionais desenvolvidas em prol da diversidade com base no princípio da equidade $(\alpha=0,828)$. Os resultados obtidos da análise fatorial geraram algumas perguntas sobre a escala: por que os itens referentes às ações com base nos princípios de igualdade e necessidade foram agrupados? Estaria a escala gerando dubiedade nos indivíduos quanto aos princípios em estudo? Após submissão da escala a novos juízes para checar a validação semântica, foram realizados ajustes nos itens 6 e 15. O passo seguinte a esse ajuste foi realizar a aplicação da escala na pesquisa final.

\subsection{A Pesquisa Final}

A pesquisa final foi composta de uma amostra de 253 indivíduos predominantemente da zona central e da zona sul de São Paulo, sendo 52\% de mulheres, 60\% de pessoas entre 21 e 30 anos, $84 \%$ de pessoas da raça branca, $85 \%$ de pessoas com superior completo e $94 \%$ de pessoas sem deficiência. O perfil predominante foi de mulheres jovens pertencentes a empresas privadas, com o cargo de analista. $O$ instrumento foi aplicado por meio do recurso digital e, também, presencialmente. O método de amostragem foi o não probabilístico e por acessibilidade.

Nessa etapa da pesquisa o instrumento utilizado foi aplicado em uma nova amostra de acordo com os mesmos procedimentos utilizados no pré-teste. Após uma análise fatorial confirmatória, novamente os itens 1 e 10 foram eliminados, ficando a escala final com 22 itens. O método de extração foi o dos Componentes Principais, a rotação utilizada foi a Varimax e optou-se por manter os fatores com carga fatorial acima de 0,45 consideradas cargas significativas (Hair, Babin, Money e Samouel, 2005). O KMO foi de 0,875 e o teste de esfericidade de Bartlett (qui-quadrado aproximado $=3498,98 ; p<0,01$ ). A matriz da anti-imagem indicou correlações satisfatórias entre 0,734 e 0,948 maiores do que 0,5 (MAS > 0,5) 0 percentual de variância explicada foi de $57,1 \%$. Os procedimentos adotados para a extração dos fatores também indicaram a existência de três fatores.

Uma nova análise fatorial foi realizada e os dados obtidos revelaram-se exatamente igual aos do préteste. O fator 1 representou a percepção de justiça distributiva diante das ações organizacionais desenvolvidas em prol da diversidade com base nos princípios da necessidade e de igualdade de oportunidades oferecidas para as mulheres e pessoas negras $(\alpha=0,939)$; 0 fator 2 representou a percepção de justiça distributiva diante das ações organizacionais desenvolvidas em prol da diversidade 
com base nos princípios da equidade $(\alpha=0,867)$ e o fator 3 que representou a percepção de justiça distributiva diante das ações organizacionais desenvolvidas em prol da diversidade com base nos princípios da necessidade e da igualdade de oportunidades oferecidas para as pessoas com deficiência $(\alpha=0,810)$. Apesar dos resultados das pesquisas terem apresentados consistência interna e atenderem aos indicadores de validação (Pasquali, 2004), entende-se que a escala ainda precisa ser mais investigada para que ela possa mensurar separadamente os três princípios de justiça distributiva sobre as ações organizacionais voltadas à diversidade (equidade, igualdade e necessidade).

\subsection{Tratamento dos Dados}

Antes de realizar os procedimentos estatísticos, os dados obtidos da amostra foram devidamente avaliados, os redundantes em mais de $85 \%$ dos itens da escala foram expurgados, garantindo assim uma precisão maior das respostas. Para verificar qual a maior tendência de respostas dos indivíduos sobre a percepção de justiça organizacional sobre as ações organizacionais que oferecem recursos e oportunidades em geral, foi realizada uma estatística descritiva tomando-se como referência a soma de respostas dos sujeitos diante dos itens que faziam referência aos três tipos de percepção em estudo: a baseada no princípio da necessidade (FatSom $\mathrm{Nec}$ ), a baseada na equidade (FatSomEqu) e a baseada na igualdade de oportunidade (FatSomOpor). Tendo em vista uma distribuição não normal (Kolmogorov-Smirnov com sig < 0,005), a mediana foi a medida central adotada.

\subsection{Análise dos Dados}

Como se pode observar na Tabela 2, houve por parte dos sujeitos da amostra uma tendência geral de discordância parcial ou concordância parcial (posicionamento entre 3,0 e 4,9 na escala) ao perceberem como justas as ações organizacionais que oferecem recursos e oportunidades à diversidade (no geral) com base nos princípios de justiça da necessidade ou da igualdade de oportunidade, no que significa uma predominância de ambiguidade, ou ainda, uma falta de clareza sobre esse assunto. No entanto, houve uma nítida tendência de concordância (posicionamento entre 5,0 e 6,0 na escala) por parte dos sujeitos de que é justo utilizar-se do princípio da equidade diante das ações que oferecem recursos e oportunidades iguais para todos.

Tabela 2: Estatística Descritiva dos Fatores Somados

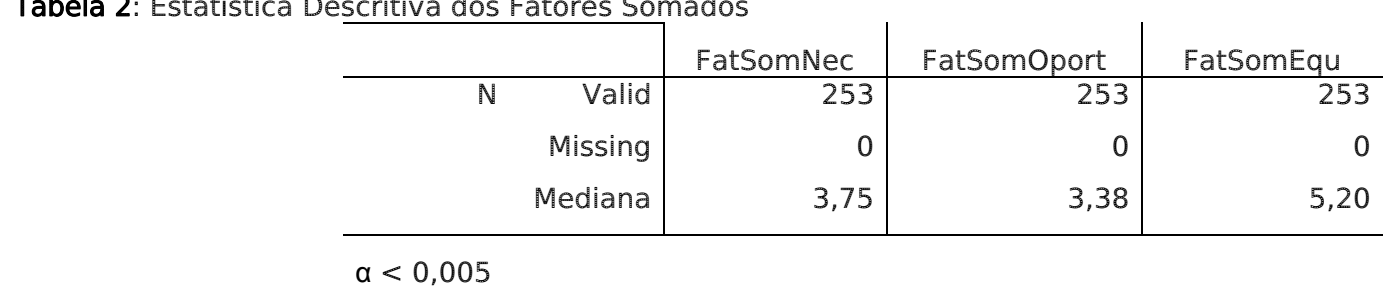

Fonte: Dados da pesquisa

Porém, quando os itens da escala foram analisados um a um, tomando-se como referência os grupos sociais em estudo (mulheres em geral, pessoas negras e pessoas com deficiência), os dados revelaram uma tendência de discordância parcial ou concordância parcial dos sujeitos (posicionamento entre 3,0 e 4,9 na escala) ao perceberem como justas as ações organizacionais que oferecem recursos e oportunidades às mulheres com base nos princípios de justiça da necessidade ou da igualdade de oportunidade. No que diz respeito às pessoas negras, houve uma tendência dos sujeitos em discordar claramente (posicionamento 2,0 na escala) da ideia de que as ações que oferecem benefícios diferenciados para atendê-las são justas (item 24), bem como, diante das ações voltadas para a contratação de tais pessoas em cargos de comando (item 12). No que diz respeito às pessoas com deficiência, houve uma tendência de perceber como justas (posicionamento 5,0 na escala) as ações que identificam as suas necessidades (item 15), assim como, as ações que as beneficiam (item 11), como as que as ajudam no desenvolvimento da carreira (itens 2 e 22).

Como visto no referencial teórico o princípio da equidade defende que a distribuição de recursos oferecidos aos indivíduos deve ser compatível aos esforços desprendidos diante do desempenho realizado pelos mesmos, ou seja, eles precisam ser baseados no mérito. Conforme destaca Billing \& Sundin (2006) o princípio da meritocracia lembra a funcionalidade do sistema capitalista, em que o indivíduo lucra conforme a sua produção. Nada mal, quando se pensa numa sociedade que oferece oportunidades iguais 
para todos, como desenvolvimento social, educacional e profissional. Mas, em uma sociedade onde tais oportunidades não são as mesmas para os seus integrantes, entende-se que tal princípio é um parâmetro que precisa ser analisado de forma mais crítica de modo que possa refletir a justiça de uma forma mais ampla.

Não se pode desconsiderar que o desempenho do indivíduo no ambiente trabalho seja um critério fundamental para que não se crie uma situação de protecionismo desmedido ou de injustiça perante outros com resultados superiores (Linnehan \& Konrad, 1999). Mas, não se pode achar que o desempenho no trabalho depende unicamente da meritocracia, ou seja, dos esforços e da boa vontade do indivíduo. Em um país onde os índices de diferenças sociais são relevantes (IBGE, 2010), não seria justo comparar o desempenho obtido por alguém que teve oportunidades de saúde e educação com alguém que não as teve. Portanto, o contexto histórico/social dos indivíduos é apontado neste trabalho como parâmetro importante que precisa ser considerado e discutido diante do assunto em questão.

\section{Testes de Hipóteses}

Os dados da pesquisa não apresentaram uma distribuição normal (Kolmogorov-Smirnov < 0,005), em virtude disso, os procedimentos estatísticos utilizados para checar as hipóteses deste trabalho foram os testes não paramétricos de Mann-Whitney e do Kruskal Wallis, ambos disponíveis no programa SPSS (versão 15). Tal análise foi realizada a partir da soma dos dados obtidos em cada um dos fatores em estudo (FatSomNec - necessidade, FatSomEqu - equidade e FatSomOpor - igualdade de oportunidade). O grau de significância adotado foi de $p<0,05$.

\section{Hipótese H1:}

A hipótese $H_{1}$ parte do pressuposto de que há diferença de percepção de justiça organizacional entre homens e mulheres diante das ações organizacionais que oferecem recursos e oportunidades à diversidade independente do sexo, da raça e de ser ou não pessoa com deficiência, baseadas no princípio da equidade. Pelos dados obtidos, de uma maneira geral não houve diferença significativa de percepção entre homens e mulheres diante de tal assertiva, porém tal diferença de fez presente entre homens e mulheres negros ou pardos não deficientes que estão na faixa de idade de 21 a 30 anos e com escolaridade superior completo ou a completar. Pelo que se pode observar a média de concordância de respostas das mulheres $(M=14,1)$ de que tais ações são justas foi maior do que a média de respostas dos homens $(M=7,5)$.

Tabela 3: Teste Etastísticos a,b,c

\begin{tabular}{l|r}
\hline & FatSomEqu \\
\hline Mann-Whitney U & 20,500 \\
Wilcoxon W & 75,500 \\
Z & $-2,510$ \\
Asymp. Sig. (2-tailed) &, 012 \\
Exact Sig. [2*(1-tailed Sig.)] &, 013 \\
\hline
\end{tabular}

b. Idade $=21-30$, Cor_Raça $=$ Parda ou negro, PCD

= Não PCD, Escolaridade = Superior

c. Grupo de variável: Sexo

$p<0,05$

Dessa forma, a hipótese $\mathrm{H}_{1}$ foi corroborada quando a variável sexo foi considerada em conjunto com as variáveis: idade, raça e escolaridade.

Ações organizacionais que oferecem recursos e oportunidades à diversidade baseadas no princípio da equidade pressupõem que todos possuem as mesmas condições de desenvolvimento e são considerados igualmente capazes independentemente do sexo, da raça e de ser ou não pessoa com deficiência (Kandola e Furleton, 1994). Em países desenvolvidos com baixos índices de diferenças sociais há uma defesa por 
ações organizacionais voltadas para a dissolução das diferenças sociais com base na meritocracia (Linnehan \& Konrad, 1999), onde prevalece o princípio da equidade todos os indivíduos, indistintamente, são avaliados sob as mesmas condições de competitividade profissional, o que faz todo sentido. Mas, sabese que não é esse o caso do Brasil.

Pesquisas revelam que mesmo tendo uma maior escolaridade as mulheres não ocupam os melhores postos de trabalho (IBGE, 2010; Instituto Ethos, 2010), em virtude disso, seria de esperar que a adoção do critério da meritocracia diante de ações organizacionais que oferecem recursos e oportunidades à diversidade não fosse reconhecido como justo, pelo menos por parte das mulheres. Mas não é bem isso o que os resultados dessa pesquisa demonstram, com exceção das mulheres negras na faixa de idade entre 21 e 30 anos. Essas mulheres revelaram mais concordância com a ideia de que tais ações são injustas do que os homens negros, talvez porque as diferenças entre os homens e as mulheres brancos não sejam tão expressivas.

A diferença de posicionamento entre homens e mulheres sob a perspectiva da raça/cor da pele diante de ações organizacionais que oferecem recursos e oportunidades à diversidade, talvez reflita uma realidade que é muito pouco discutida na academia e no próprio contexto organizacional brasileiro.

Ao investigar o comportamento da desigualdade racial no Brasil no período 1992 a 2005 a Organização Internacional do Trabalho (OIT, 2006), com base nos dados da Pesquisa Nacional por Amostra de Domicílios - PNAD do IBGE, revela que as dificuldades enfrentadas pelas mulheres negras para colocar-se no mercado de trabalho tendem a se mostrar maiores, com menor crescimento relativo de sua taxa de ocupação e de rendimentos, quando comparadas aos homens (brancos e negros) e às mulheres brancas. No que diz respeito à taxa de atividade a participação dos homens mantém-se maior do que a participação das mulheres, independente da cor/raça. Mas há de se considerar que a taxa de atividade das mulheres brancas teve um crescimento de $17,15 \%$ contra 13,15\% das mulheres negras; já a taxa de ocupação das mulheres brancas teve um crescimento de $13,1 \%$, contra $5,9 \%$ das mulheres negras. A taxa de desemprego entre as mulheres negras foi de 10,0\%, em 1992, e atinge 15,8\%, em 2005, com um crescimento de 58,0\%. Entre os homens negros, o desemprego atingiu 6,3\%, em 1992, e passou para $8,5 \%$, em 2005, - acréscimo de 33,9\%. No mesmo período, a taxa de desemprego dos homens brancos cresceu $25,8 \%$ e das mulheres brancas, $38,8 \%$.

Na conferência de Durban em 2000 o IPEA (Instituto de Pesquisas Econômicas Aplicadas) mostrou que a taxa de desemprego das mulheres negras no Brasil $(16,5 \%)$ era maior que a de mulheres brancas (12,53\%), segundo a Pesquisa Nacional por Amostra de Domicílios (Pnad) do IBGE (Instituto Brasileiro de Geografia e Estatística) de 1999. Passados dez anos, o Censo IBGE (2010) revela que as mulheres negras continuam sendo as que mais sofrem com a falta emprego. Problema que se espalha por todo país, ou seja, pouca coisa tem sido feita para reverter tal situação. Nesse sentido, a fala de Soares em 2000 continua valendo em tempos atuais: "as mulheres negras arcam com todo o ônus da discriminação de cor e de gênero e ainda sofrem mais com a discriminação setorial-regional-ocupacional".

Quanto ao fato de não haver diferenças entre homens e mulheres não negros de que as ações organizacionais em prol da diversidade baseadas na equidade são justas, alguns estudos estrangeiros revelam que grupos sociais preteridos ou subrepresentados nas empresas podem negar a existência da sua desigualdade perante outros pelo receio de serem estigmatizados como incapazes ou incompetentes (Heilman, Block \& Lucas, 1992). Neste trabalho não há condições de afirmar que esse seja o caso das mulheres não negras, mas torna-se importante a realização de futuros estudos para investigar melhor esse fenômeno.

\section{Hipótese H2:}

A hipótese $\mathrm{H}_{2}$ parte do pressuposto de que há diferença de percepção de justiça organizacional entre homens e mulheres diante das ações organizacionais que oferecem recursos e oportunidades à diversidade baseadas no princípio da igualdade de oportunidade. Pelos dados obtidos (Tabela 4), houve diferença de percepção significativa entre os homens e as mulheres em geral da amostra em estudo diante de tal assertiva, sendo que a média de respostas de concordância das mulheres $(M=136,4)$ de tais ações como justas foi maior do que a média de respostas dos homens $(M=116,8)$.

Quando a variável sexo foi analisada em conjunto com as variáveis: idade e escolaridade (Tabela 5), a diferença de percepção de justiça entre homens e mulheres também se fez presente. Pelos dados obtidos, 
houve uma diferença significativa de percepção entre homens e mulheres não PCDs (pessoas com deficiência) que estão na faixa de idade de 30 a 40 anos e com escolaridade de pós-graduação. Em ambos os casos, a média de concordância de respostas das mulheres a essa assertiva $(M=23,6 ; M=16,8)$ foi respectivamente maior do que a média de respostas dos homens $(M=13,9, M=10,1)$.

Tabela 4: Teste Estatístico. a

\begin{tabular}{l|c}
\hline & FatSomOport \\
\hline Mann-Whitney U & 6751,500 \\
Wilcoxon W & 14254,500 \\
Z & $-2,133$ \\
Asymp. Sig. (2-tailed) &, 033 \\
\hline
\end{tabular}
a. Grupo de variável: Sexo $p<0,05$

Tabela 5: Testes Estatísticos. a,b,c,d

\begin{tabular}{r|r|r|r}
\hline & FatSomOport & FatSomOport & FatSomOport \\
\hline Mann-Whitney U & 90,000 & 40,500 & 5756,500 \\
Wilcoxon W & 181,000 & 131,500 & 12197,500 \\
Z & $-2,473$ & $-2,264$ & $-2,372$ \\
Asymp. Sig. (2-tailed) &, 013 &, 024 &, 018 \\
Exact Sig. [2*(1-tailed Sig.)] &, 013 &, 022 &, 018 \\
\hline
\end{tabular}
a. Grupo de variável: sexo
b. Idade 3040 anos
c. Escolaridade: pós-grad
d. Não PCD
$p<0,005$

Dessa forma, a hipótese $\mathrm{H}_{2}$ foi corroborada quando considerada a variável sexo, e também, quando a variável sexo foi analisada em conjunto com as variáveis: idade, escolaridade e não ser PCD.

A diferença de percepção de justiça sobre as ações organizacionais voltadas à diversidade com base no princípio da igualdade de oportunidade, talvez reflita a consciência por parte das mulheres de que elas não possuem as mesmas chances dos homens, quando estão numa fase da vida em que poderiam vir a ocupar cargos mais estratégicos e de poder nas organizações, haja vista, os dados do Ethos (2010) apresentados anteriormente. No entanto, parece um contratempo pensar que a maioria das mulheres desta pesquisa tem consciência da desigualdade de oportunidades no contexto organizacional frente às oportunidades oferecidas aos homens, mas ainda assim, percebe como justas as ações organizacionais que oferecem oportunidades com base na equidade, como visto na análise da hipótese anterior. Este é um fenômeno que precisa ser estudado, pois não parece claro que as mulheres, principalmente as não brancas, tenham posicionamentos aparentemente contraditórios. Estudos futuros serão necessários para um melhor entendimento dessa situação.

\section{Hipótese H3:}

A hipótese $\mathrm{H}_{3}$ parte do pressuposto de que há diferença de percepção de justiça organizacional entre homens e mulheres diante das ações organizacionais que oferecem recursos e oportunidades à diversidade baseadas no princípio da necessidade. Pelos dados obtidos, não houve diferença significativa de tal percepção, nem quando a variável sexo foi analisada em conjunto com outras variáveis tais como: idade, escolaridade e raça. No entanto, quando foi analisada a percepção de justiça dos indivíduos sobre os itens do instrumento de pesquisa referentes ao princípio da necessidade (para mulheres, para pessoas negras e para as pessoas com deficiência), houve uma diferença significativa entre homens e mulheres diante do 
item 15, que faz menção as ações organizacionais voltadas para a formação de comitês a fim de identificar as necessidades das pessoas com deficiência. A média de respostas de concordância dos homens em relação a essa assertiva $(M=136,6)$ foi maior do que a média de respostas das mulheres $(M=118,0)$.

Tabela 6: Testes Estatísticos. a

\begin{tabular}{l|c}
\hline & Item15.NecessidadePCD \\
\hline Mann-Whitney U & 6820,000 \\
Wilcoxon W & 15466,000 \\
Z & $-2,106$ \\
Asymp. Sig. (2-tailed) &, 035 \\
\hline
\end{tabular}

Grupo de variável: Sexo

$P<0,05$

Dessa forma, a hipótese $\mathrm{H}_{3}$ foi corroborada nesse estudo, somente perante o item da escala que faz menção as ações organizacionais voltadas para a formação de comitês a fim de identificar as necessidades das pessoas com deficiência.

O fato das ações organizacionais que oferecem recursos e oportunidades para as pessoas negras terem sido percebidas claramente como não justas, reflete uma tendência das pessoas pesquisadas em desenvolver um tratamento igualitário em relação às pessoas negras, e isso não seria nada mal, se todas as pessoas brancas e negras tivessem tido o mesmo nível de desenvolvimento histórico no país, assim como, as mesmas condições e oportunidades no aspecto profissional, no entanto, se sabe que no Brasil não é esse o caso (IBGE, 2010; Instituto Ethos, 2010), dessa forma tal tratamento igualitário parece convergir ao mito da democracia racial (Guimarães, 1997), como forma de eliminar ou negar as diferenças existentes entre esses grupos de identidade.

Alves e Galeão-Silva (2004) ressaltam que a negação às pessoas negras nesse país acontece de várias formas e de maneira sutil e se ela não for admitida nas empresas e na sociedade, não se pode ir muito longe. Entende-se neste trabalho que o tratamento dado aos indivíduos pertencentes aos mais diferentes grupos sociais não pode ser o mesmo, mas por outro lado, tratá-los diferentemente requer muito cuidado. É necessário ter clareza, é preciso por as “cartas à mesa" para falar sobre esse assunto, do contrário, as palavras ditas em torno do assunto serão meras demagogias ou podem dar margem ao surgimento de discriminações. No atual cenário brasileiro não basta falar que existem diferenças de oportunidades entre as pessoas brancas e as negras, ou entre os homens e as mulheres, é preciso entender até onde as pessoas são diferentes para que sejam tratadas de modo diferente, e até onde são iguais, para serem tratadas como iguais. Desse modo, estudos realizados para conhecer os recursos e as oportunidades que tais grupos demandam das empresas, bem como, abrir discussões com a iniciativa privada sobre a viabilidade em atendê-los a fim de que essas ações tenham foco e sejam eficazes, podem trazer contribuições importantes em torno dessa temática.

Neste trabalho, as únicas ações organizacionais em prol da valorização da diversidade que foram percebidas como justas foram às voltadas para o grupo de pessoas com deficiência. Ao que parece, ações voltadas para a contratação e para o desenvolvimento profissional de pessoas pertencentes a esse grupo social foram bem vistas; o que é muito bom, pois essas ações foram endossadas. No entanto, esse dado parece revelar que a visão de quem é diverso para os sujeitos dessa amostra de pesquisa, ainda é muito incipiente, volta-se para uma visão primária (Loden \& Rosener, 1991), ou seja, aquela que diz respeito às características físicas dos indivíduos. Mas, a diversidade humana vai muito além do que os olhos podem ver. Desse modo, ainda há muito que avançar sobre esse assunto no Brasil, mas será preciso quebrar barreiras visíveis e invisíveis para falar sobre as ações voltadas às diferenças humanas nos espaços organizacionais, fica então o convite para quem queira aceitar esse desafio.

\section{Discussão dos Resultados}

Este artigo teve como objetivo geral conhecer a percepção de justiça distributiva de indivíduos diante das ações organizacionais que oferecem recursos e oportunidades à diversidade (às mulheres, às pessoas 
negras e às pessoas com deficiência), e secundariamente, investigar se essa percepção difere entre homens e mulheres. Os trabalhos desenvolvidos visando tal objetivo apresentaram contribuições relevantes que permitiram avanços na academia e no mundo corporativo sob diferentes perspectivas.

Sob a perspectiva da academia, pode-se dizer que o estudo sobre a percepção de justiça distributiva desenvolvido neste trabalho abriu espaços para discussões mais amplas sobre as diferentes crenças utilizadas pelos indivíduos, quando estes julgam como justas ou injustas as ações que as organizações desenvolvem para distribuir recursos e oportunidades à diversidade, considerando-se os princípios da: equidade, igualdade e necessidade (Miller, 1976). Além de muito pouco explorada, tal percepção vem sendo abordada por autores nacionais com ênfase no princípio da equidade (Rego, Maria, Leite, Freire \& Vieira, 2002; Mendonça \& Tamayo, 2004; Almeida, Silva, \& Santos, 2006). Nesse sentido, este trabalho deu um passo a mais, ao explorar diferentes maneiras dos indivíduos apreenderem a realidade em questão e revelou que muitas outras investigações serão necessárias para esclarecer o que ainda está obscuro em torno dessa temática, como a aplicabilidade dos princípios da igualdade de oportunidade e da necessidade perante tais ações, uma vez que não houve distinção de percepção por parte dos indivíduos pesquisados diante das ações que contemplaram tais princípios.

Os dados obtidos da pesquisa realizada neste trabalho também contribuíram na medida em que apresentaram resultados semelhantes aos obtidos em outras pesquisas. Eles corroboraram com Pereira (2008) na medida em que as ações organizacionais que oferecem recursos e oportunidades à diversidade (mulheres, pessoas negras e pessoas com deficiência) foram predominantemente percebidas como justas, quando baseadas no princípio da equidade, embora a maioria dos indivíduos pesquisados tenha o perfil que se caracteriza pela mulher branca, jovem, com escolaridade superior (completa ou a completar) e que está inserida no mercado de trabalho. Seria interessante realizar outros estudos com outra caracterização de amostra para verificar se tal percepção é ou não confirmada.

Secundariamente, os achados da pesquisa revelaram que a percepção de justiça sobre as ações organizacionais voltadas à diversidade modifica-se não só de acordo com o sexo e a raça/etnia dos supostamente beneficiários por tais ações, como revelaram alguns estudiosos estrangeiros (Richard \& Kirby, 1997; Leck, Saunders \& Charbonneau, 1996; Vermeulen \& Coetzee, 2006), mas também, se tais beneficiários têm ou não alguma deficiência. Além disso, tornou-se relevante considerar a idade e a escolaridade dos pesquisados. Foi possível verificar que, sob o princípio da equidade, houve diferença de percepção de justiça entre os homens e as mulheres, quando a variável sexo foi agrupada às variáveis: raça, idade e escolaridade. E sob o princípio da igualdade de oportunidade, essa diferença se fez presente não só quando a variável sexo foi analisada isoladamente, mas também quando agrupada às variáveis: idade e escolaridade. Por esses achados, entendeu-se que o momento de vida e o grau de instrução foram relevantes para o estudo de tal percepção. Isso faz sentido, quando se percebe que as ações em estudo ainda são incipientes no Brasil e que muitos ainda não sabem direito do que elas se tratam (Pereira \& Hanashiro, 2010). Daí recomenda-se que em estudos futuros sobre essa temática essas variáveis sejam consideradas.

Sob a perspectiva prescritiva este trabalho abre novas perspectivas para dar continuidade aos estudos que possam validar a escala de percepção de justiça distributiva diante de ações organizacionais que oferecem recursos e oportunidades à diversidade, uma vez que ainda não há clareza sobre o quanto elas são ou não justas no contexto brasileiro, ao se considerar isoladamente os princípios de igualdade de oportunidade e da necessidade. Nesse sentido ainda há muito que avançar. Entende-se que essa escala é de muita importância para a realização de diagnósticos em empresas que pretendam conhecer a percepção de seus funcionários sobre tais ações e também sobre o que eles pensam sobre o assunto. Saber sobre tal percepção ajuda as empresas a gerenciar as suas ações em prol da diversidade de forma mais norteadora e efetiva.

Pelo exposto, entende-se que este trabalho avança na medida em que ele apresenta dados que descortinam parte de uma pequena realidade. Embora singelo, ele pode servir de estímulo para a abertura de novos horizontes, bem como, a novas fronteiras de pesquisas.

\section{Considerações Finais}

A conclusão desse trabalho remete a duas considerações finais importantes. A primeira delas diz respeito aos constructos utilizados nesta pesquisa. Pelos dados obtidos da análise fatorial é possível 
desenvolver questões importantes: (1) será que as pessoas não perceberam com clareza a diferença entre as ações organizacionais que oferecem recursos e oportunidades para as mulheres em geral e para as pessoas negras baseadas, quando considerados os princípios de justiça baseados na igualdade e na necessidade? Ou ainda, (2) será que as pessoas não perceberam com clareza a diferença entre tais ações, porque entendem que elas somente são justas quando oferecem as mesmas oportunidades e atendem as mesmas necessidades para tais grupos sociais? No primeiro caso se pode imaginar que a escala utilizada na pesquisa não está suficientemente objetiva para mensurar os princípios de justiça propostos, e nesse caso, cabe o desenvolvimento de novos estudos para o aprimoramento e validade da mesma. No segundo caso, o que se pode imaginar é que de fato não há um reconhecimento por parte dos sujeitos de que os grupos de mulheres em geral e o grupos de pessoas negras possuem necessidades que precisam ser diferenciadas e reconhecidas. Acredita-se nesse trabalho que resultados de pesquisas futuras irão convergir para o segundo caso, pois se acredita que no Brasil as pessoas não valorizam e nem costumam pensar nas necessidades provenientes dos seus grupos sociais. Mas, essas são meras conjecturas. Portanto, é recomendável que outros estudos sejam feitos para investigar mais a fundo tais fenômenos.

A segunda consideração diz respeito às limitações do trabalho. Em razão do método de amostragem não probabilístico, não se pode fazer qualquer generalização dos resultados obtidos. Espera-se, então, que os dados obtidos possam não só gerar discussões, reflexões, mas despertar o interesse pela realização de outros estudos sobre a percepção de justiça distributiva sobre as ações organizacionais que oferecem recursos e oportunidades à diversidade.

\section{Referências}

Almeida, G. DE O.; Silva, A.M.M. da; \& Santos, D.M. dos S. (2006). Justiça Organizacional - Relações com a Ineficácia Profissional, Comprometimento Afetivo e Auto Percepção de Saúde Geral. IX Semead-Seminários em Administração Anais. FEA-USP, São Paulo.

Alves, M. A.; \& Galeão-Silva, L. G. A.(2004). Crítica da gestão da diversidade nas organizações. Revista de Administração de Empresas, São Paulo, 44(3), pp.20-29.

Assmar, E.M. L.; \& Ferreira, M.C. (2005). Justiça Organizacional: uma Revisão Crítica da Literatura. Psicologia: Reflexão e Crítica, 18(3), pp. 443-453.

Bateman, T. S.; \& Snell, S. A. (2008). Administração: construindo vantagem competitiva. São Paulo: Atlas.

Billing,Y.D.; \& Sundin, E. (2006). From managing equality to managing diversity. In: Konrad, A.; Prasad P.; \& Pringle, J.K. Handbook of workplace diversity, pp.105-113.

Bond, M. A., \& Pyle, J. L. (1998). Diversity dilemmas at work. Journal of Management Inquiry, 7(3), pp.252269.

Colquitt, J. A. (2001). On the dimensionality of organizational justice: A construct validation of a measure. Washington, Journal of Applied Psychology. 86 (3); pp. 386-400.

Cox, T. Jr. (1991). The Multicultural Organization. Academy of Management Executive. 5(2), pp. 34-47.

Deutsch, M. (1985). Distributive Justice: a Social-Psychological perspective.Yale University Press, New Haven: CT.

Deutsch, M. (1985). Distributive Justice: a Social-Psychological perspective. Yale University Press, New Haven: CT.

Folger, R. (1986). Rethinking equity theory: a referent cognitions model. In: H.W.Bierhoff, R.L. Cohen, \& J. Greenberg (Eds), New York, Justice in Social relations, pp. 145-162.

Guimarães, A. S. A. (1997). A Desigualdade que anula a desigualdade: notas sobre a ação afirmativa no Brasil. In: Souza, J. (org.). Multiculturalismo e racismo: uma comparação Brasil-Estados Unidos. Brasília: Paralelo 15, pp.233-242.

Hair, Jr, J.F., Babin, B., Money, A.H. \& Samouel, P. (2005). Fundamentos de métodos de pesquisa em administração. Porto Alegre: Bookman.

Heilman, M. E., Block, C. J., \& Lucas, J. A. (1992). Presumed incompetent? Stigmatization and affirmative action efforts. Journal of Applied Psychology, 77(4), 536-544.

Homans, G. C. (1961). The Humanities and the Social Sciences; joint concern with "individual" and values the arts distinct from social science distinctions of social status. The American Behavioral Scientist (pre1986), 4(8). 
IBGE-Instituto Brasileiro de Geografia e Estatística. Censo 2010. Disponível em: http:www.ibge.gov.br, acesso em: 05/05/2010

Instituto Ethos. (2010). Perfil Social, Racial e de Gênero das 500 Maiores Empresas do Brasil e suas Ações Afirmativas - Pesquisa 2010. Benjamim S. G.; Helio G. F., São Paulo: Instituto Ethos, 2010.

IPEA - Instituto de Pesquisa Econômica Aplicada. (2008). Retrato das Desigualdades de Gênero e Raça (2008). Pinheiro, L. et al. 3. ed. Brasília: IPEA: SPM: UNIFEM.

Ivancevich, J. M., \& Gilbert, J. A. (2000). Diversity management time for a new approach. PublicPersonnel Management, 29(1), pp.75-92.

Ivancevich, J.M. \& Gilbert, J.A.(2000). Diversity management time for a new approach. Public Personnel Management, $9(1)$, p. 75, Spring.

Kandola, R.; Fullerton, J. (1994). Diversity: more than just an empty slogan. Personne/ Management, 26(11), pp.46-50.

Kaufmann, R. F. M. (2007). Ações afirmativas à brasileira: necessidade ou mito? A implementação para negros como mecanismo concretizador de direitos fundamentais. Uma análise histórico-jurídicocomparativa do negro nos Estados Unidos da América e no Brasil. Jus Navigandi, Teresina, 11(1455), pp.267-285.

Leck,J.D.; Saunders, D. M; \& Charbonneau, M. (1996). Affirmative action's programs: an organizational justice perspective. Journal of Organizational Behavior, 17, p.79-89.

Lerner, M.J. (1975). The justice motive in social behavior: introduction. journal of Social/ssues, 3(1), pp.1-20.

Leventhal, G.S. (1976). Fairness in social relationships. In: Thibaut, J.W.; SPENCE, J.T. and Carson,R.C.(Eds) Comtemporary Topics in Social Psychology. General Learning. Press Morrsiton, NJ, pp. $21-239$.

Linnehan, F.; \& Konrad, A.M. (1999). Diluting diversity. Journal of Management Inquiry, 8(4). pp. $399-414$. Loden, M., \& Rosener, J. (1991). Workforce America. Managing employee diversity as a vital resource. Homewood, IL: Irwin.

Mendonça, H.; \& Tamayo, Á. (2004). Percepção de Justiça e Reações Retaliatórias nas Organizações: Análise Empírica de um Modelo Atitudinal. Revista de Administração Contemporânea. São Paulo, 8 (2), pp.117-135.

Miller, D. (1976). Social justice. Claredon. Oxford.

Moehlecke, S. (2002). Ação afirmativa: história e debates no Brasil. São Paulo, Cadernos de Pesquisa, n.117, pp. 197-217.

OIT - Organização Internacional do Trabalho. (2006). Trabalho decente e desigualdade racial no Brasil, Release- OIT, Nov, 2006.

Pasquali, L.(2004). Psicometria.Teoria dos testes na psicologia e na educação.Petrópolis, Vozes.

Pereira, J. B. C. (2008). A relação entre as dimensões de justiça organizacional e as atitudes dos indivíduos diante da diversidade, 2008. 332f. Tese (Doutorado em Administração de Empresas) - Centro de Ciências Sociais e Aplicadas da Universidade Presbiteriana Mackenzie, São Paulo.

Pererira, J.B.C.; Hanashiro, D.M.M. (2010). Ser ou não Ser Favorável às Práticas de Diversidade? Eis a Questão. RAC - Revista de Administração Contemporânea, v. 14, n. 4, pp. 670-683.

Rego, A. (2002). Comprometimento afectivo dos membros organizacionais: o papel das percepções de justiça. Revista de Administração Contemporânea, 6. 209-241.

Rego, A.; Maria T.; Leite, R.; Freire, C.; \& Vieira, A.(2002). Justiça nas Organizações: um modelo tetradimensional. RPot, São Paulo, 2(2), pp.113-142.

Richard, O. C., \& Kirby S. L. (1997). Attitudes of white American male students toward work force diversity programs. The Journal of Social Psychology, 137(6), pp.784-786.

Romero, S. (1980). História da Literatura Brasileira. Ed. Rio de Janeiro: José Olympio.

Sabbagh, C. (2002). A taxonomy of normative and empirically oriented theories of distributive justice. Social Justice Research, 14 (3), pp.237-263.

Schwartz,S.H. (1975). The justice of need and activation of humanitarian norms. journa/ Social/ssues, 31, pp.111-115.

Sen, S. \& Bhattacharya C. B. (2001). Does Doing Good Always Lead to Doing Better? Consumer Reactions to Corporate Social Responsibility. Journal of Marketing Research, 38(2), pp.225-244. 
Soares, S. S. D. O perfil da discriminação no mercado de trabalho. Homens negros, mulheres brancas e mulheres negras. Estudos Sociais do IPEA, Texto para discussão no 769, 2000.

Thomas, D. A., \& Ely, R. J. (1996). Making differences matter: a new paradigm for managing diversity. In The Jossey-Bass reader on educational leadership (Chap. 19, pp. 197-210). San Francisco: Jossey-Bass

Valentim, D. (2005). Ações Afirmativas: um instrumento de promoção da igualdade. In Candau, V.; \& Gabriel, C. (Eds.) Cultura(s) e Educação: entre o crítico e o pós-crítico. Rio de Janeiro: DP\&A, pp. $151-165$

Vermeulen, L. P.; \& Coetzee, M. (2006). Perceptions of the dimensions of the fairness of affirmative actions:a pilot study. South African Journal Business Manage, 37(2), pp.53-65. Thomas, D. A., \& Ely, R. J. (1996). Making differences matter: a new paradigm for managing diversity.In The Jossey-Bass reader on educational leadership, pp. 197-210. San Franciso:Jossey-Bass.

Wilson, T. C. (2006).Whites' opposition to affirmative action: rejection of group-based preferences as well as rejection of blacks. Social Forbes, 85(1), pp.111-120. 